\title{
Education and Peacebuilding: Analysis Based on Theory and Big Data
}

\author{
Xiaofan Hong ${ }^{1, *}$ \\ ${ }^{1}$ University of Manchester, Manchester, United Kingdom, M15 6PF \\ *Corresponding author. Email:xiaofan.hong@student.manchester.ac.uk
}

\begin{abstract}
Education is always thought to be an effective method that can civilize human beings [1], generate national unity [2] and liberate people from the innocent and savage stage [3]. To explore whether educated people are less likely to use physical forces in conflicts and to what extent can education contributed to regional stability and peace, it is important to investigate thoroughly the casual relationship between some significant indicators of modern education and the mainstream index about national stability. This essay will firstly discuss the traditional understanding of education and its impact on peacebuilding, which includes the theories of Nationalism, Realism, and Darwinism. Subsequently, by introducing big data analysis, it will demonstrate the linear relationships between the rates of tertiary attainment, early childhood enrolment, years of schooling, and shares of government expenditure of states and their ranks in the Fragile States Index (FSI) to verify the effectiveness of education on peace building. This essay will so conclude that though education has been thought to be significant to national stability and unity, it only has moderate influence on improving states' frangibility. Moreover, a higher early year enrolment rates has a relatively prominent link to states' prosperity while a higher tertiary educational completion rate might result in a higher probability of unrest.
\end{abstract}

Keywords: education, peacebuilding, Fragile States Index (FSI), stability, development

\section{INTRODUCTION}

In traditional Chinese culture, educated people are always thought to be more polite and civilized while people of little education are not. To explore to what extent can education civilize people, especially constrain their urge to use physical and armed force in conflict and how much can education contribute to regional stability, this essay will discuss the influence of education on peacebuilding. Two methodologies are used in this work: firstly, this essay will analyse the theoretical explanation of how education can act on human behaviours from three aspects: Functionalism, Realism, and Interpretivism. Secondly, a large amount of data has been collected from the official database such as The World Bank, UNESCO, and Our World in Data. By comparing the rates of certain indicators of education of states and their rank in the States Fragile Index of the same year, four rough relationships between education and the stability of states are illustrated in the linear correlation graphs. These graphs are drawn using excel functions with the FSI Rank in the $\mathrm{x}$-axis and the value of the indicator of education in the $y$ axis. This essay is a combination of subjective and objective aspects of education's influence on peacebuilding. It can provide diverse thoughts for researchers to explore further on this topic.

\section{THE IMPACT OF EDUCATION ON PEACEBUILDING}

Scholars have long disputes on the function of education. While functionalism believes that education smooth the mechanical solidarities of society, critical perspectives hold pessimistic views on it. To functionalists such as Durkheim, Webber, and Parsons, educational institutions play important roles in creating social harmony [4]. Education helps create 'value consensus', which transforms and assimilates values and norms from one generation to another. This process has a political and economic impact on social development [5]. Durkheim understands the function of education as 'sustenance the social system'(ibid) by teaching the value and culture of success to students while preparing different kinds of workers for society [6]. In this case, students are trained to be specialized in various fields. They cooperate and form an interdependent, equilibrium, and harmonious society, which contribute to the stability 
of the states. On the other hand, some critical perspectives might critique this optimistic understanding of educational equality. They argue that students hold a different level of access to education based on their social status. It means that educational resources are always unevenly distributed. People in some areas are more likely to access better education than others. This can be a result of gender, income [7], region [8], ethnics and so on. In this case, education can't lessen social inequality and conflicts but tense them and create more contradictions and disputes. Nevertheless, education generates value consensus on labour reproduction(Bowles and Gintis, 1976 cited in Foley et al., 2015). The ideologies carried by education constructs a reasonable social frame of working and earning, which helps to keep the entire society to be in peace and stability.

Darwinism and some classical realists have given another explanation to the intrinsic reason of conflicts. In Darwin's (1859) 'The origin of Species', he viewed the natural world as full of competition. Because of the limited number of natural resources in a certain place. Struggling for resources can happen within and among species. As there isn't a central power to distribute these essential resources equally, the pursuit of existence can lead to harsh conflicts such as physical combats between living creatures [11]. Likewise, some realism scholars such as G. Lowes Dickinson and Edward Vose Gulick (cited in Donnelly, 2015)understand the world as an anarchic society without a central government to maintain the international order. States see each other as competitors or enemies, they try their best to pursue the 'absolute gain'[13], which can easily lead to a vicious circle of security dilemmas-a vicious situation in which actors accumulate military power for defensive purposes under the perception of threats come from other actors. States so get involved in a swirl of confrontation, comparisons, and threats due to the progress of the balance of soft and hard power[14]. Competition and conflicts here are seen as a part of human nature by some thinkers such as Thomas Hobbes [15] and Rosen S.P (2009). However, as war doesn't usually occur in some nations compared with others, conflicts are thought to be culturally based rather than inherent [17]. Education might play an important role in socializing citizens.

According to Marxism theories, education creates an ideology that helps to generate common sense among people [18]. It can influence people's consciousness and assimilate dissidents. While working and oppression are treated as a common value in the working class, the ruling class can easily squeeze benefits from the proletariats without violence. Proletariats are usually taught to working hard to gain better life inside school and family. Ideologies are used in their working place to generate their working efficiency [19], which includes awarding, professional status, reputations, titles and so on. The working culture among them also alienates their natural pursuit of freedom. As Leslie, King and Clair (2019) stated that 'work-life ideologies are consequential because they affect individuals' work-life preferences and how they make sense of demands and resources, which, in turn, affect work-life conflict and enrichment.'. Another function of education is assimilation. It is more common in post-war governing. Some of the most common strategies including unify official language and letters, history teaching, and nationalism building (flags, songs, emblems). Similar people are more likely to build common trust [21], so educate citizens in a standard way increase their similarities and so reduce the chance of disputes and conflicts.

When people witness each other as less alien and trustworthy, they may have a larger chance to cooperate harmoniously. This kind of peace is all based on the subjective perception of actors involved in the relationship. Alexander Wendt(2013) so noted that 'Anarchy is what states make of it'. When actors perceive each other as friends, their relationship is less fragmented, they are more willing to join regimes, become partners, and form collective security, such as NATO, FVEY and EU [23]. These member states usually experience similar education consists of religions, diplomatic history, common languages, cultures, aesthetics, philosophy and so on. Based on this, collaboration and negotiation can become an advanced strategy in the competition of the balance of power. As states chose to work out problems peacefully and diplomatically, internal conflicts are rarely resolved by force. This section has attempted to provide a theoretical explanation about the function of education on constraining human's impulsion of using force in the competition. As it shows above, education has a reasonable influence on peacebuilding. In the next section, this paper will explore more about the effectiveness of education on states' stability.

\section{THE STRENGTH OF EDUCATION ON PEACEBUILDING \& DISCUSSION}

Turning now to the big data analysis of how much can education act on regional stability and peace. This section will only focus on the states that occur in the Fragile States Index Rank 2017-2019 and compare the relationship of the rank of each state in the certain year with its Tertiary attainment rate, Early education enrolment rate, Average years of schooling, and the Share of government expenditure of that year. Four linear correlation graphs are shown below.

The FSI Rank is an index that measures the risk and vulnerability of states based on their political, economic, social, and military status. 


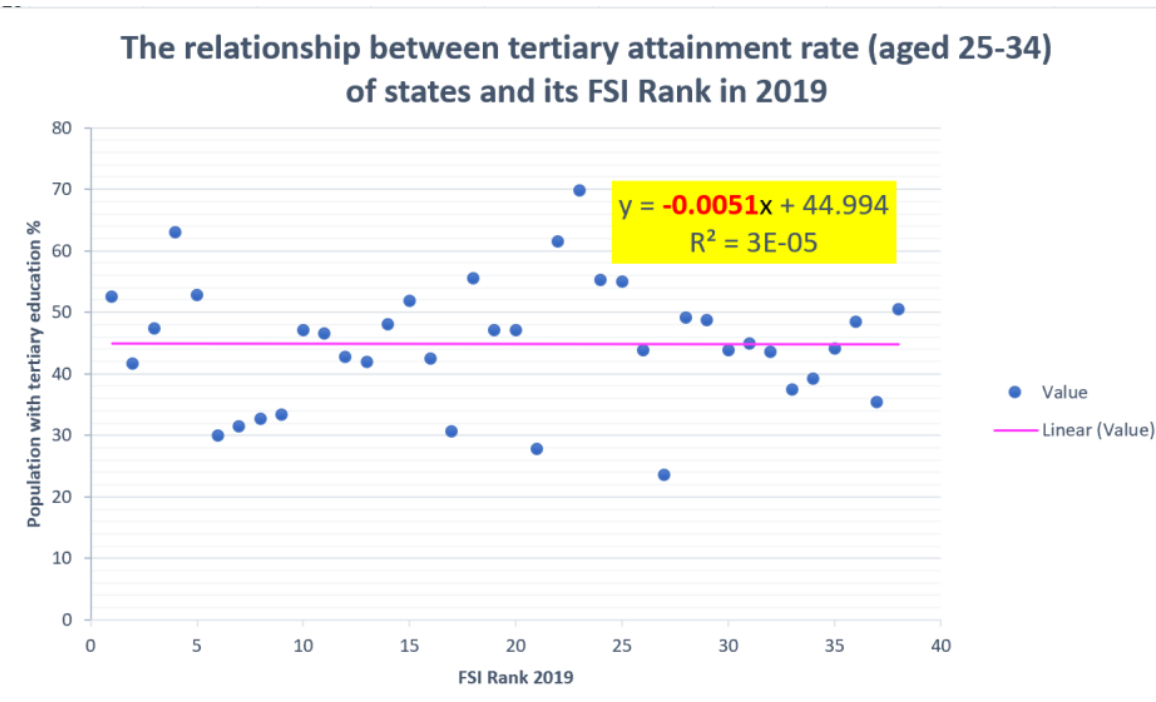

Figure 1 Tertiary attainment \& FSI Rank 2019

By collecting and analysing the data of people aged 25-34 from 39 OECD states [24], the first graph demonstrates a slightly negative correlation between the tertiary attainment rate and its FSI Rank in 2019. It shows that higher education may have a negative influence on states' stability. Silber and Bhatt's (2007, cited in Sas et al., 2020) study showed that most radicalized people have attended tertiary education while the study comes from
Gill (2007, ibid) suggests that there wasn't a clear demographic profile between educational level and radical extremists. This dialectic situation corresponds exactly to the relationship that goes to 0 in the graph. So far, we can know that having a higher degree of education has little to do with national stability. Possible influence factors can be the unequal quality of education.

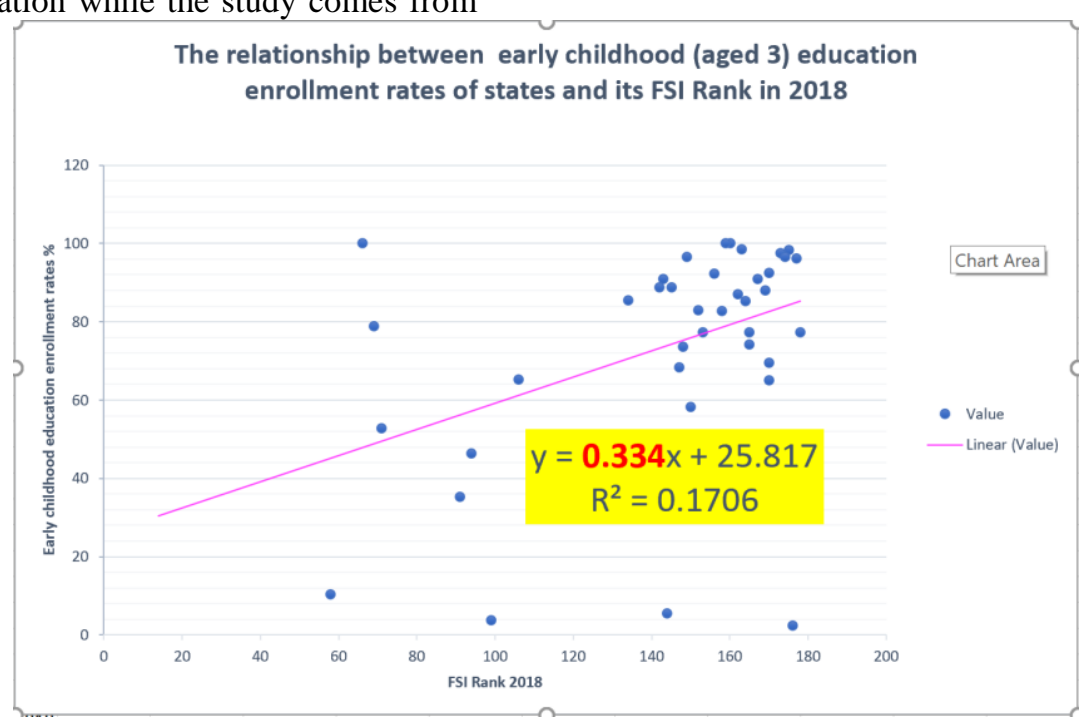

Figure 2 Early education enrolment \& FSI Rank 2018

In the second graph, an obvious and positive correlation can be seen between the early childhood (aged 3) education enrolment rates [26] and states' FSI Rank (2018). This graph compares the results of 46 OECD states with its FSI Rank in 2018. It demonstrates that the higher rate citizens gain in education at an early stage, the less fragile this state would be. Study shows that young adults are more likely to engage in violent activities such as terrorism and armed conflicts (Schönteich, 1999 cited in Sas et al., 2020). Schooling occupies their time on one hand and wears their physical power and impulsion of using force on the other. Therefore, education can somehow guide them to use alternative solutions while facing conflicts and disputes. For example, there is always administration and principles at school, the use of force is usually discouraged and punished. The earlier children adapt to this pattern in a small society, the less likely they are to be violent at large. Meanwhile, the norm of non-violence can be implanted in citizens' minds at an early stage which can influence their behaviour later. 


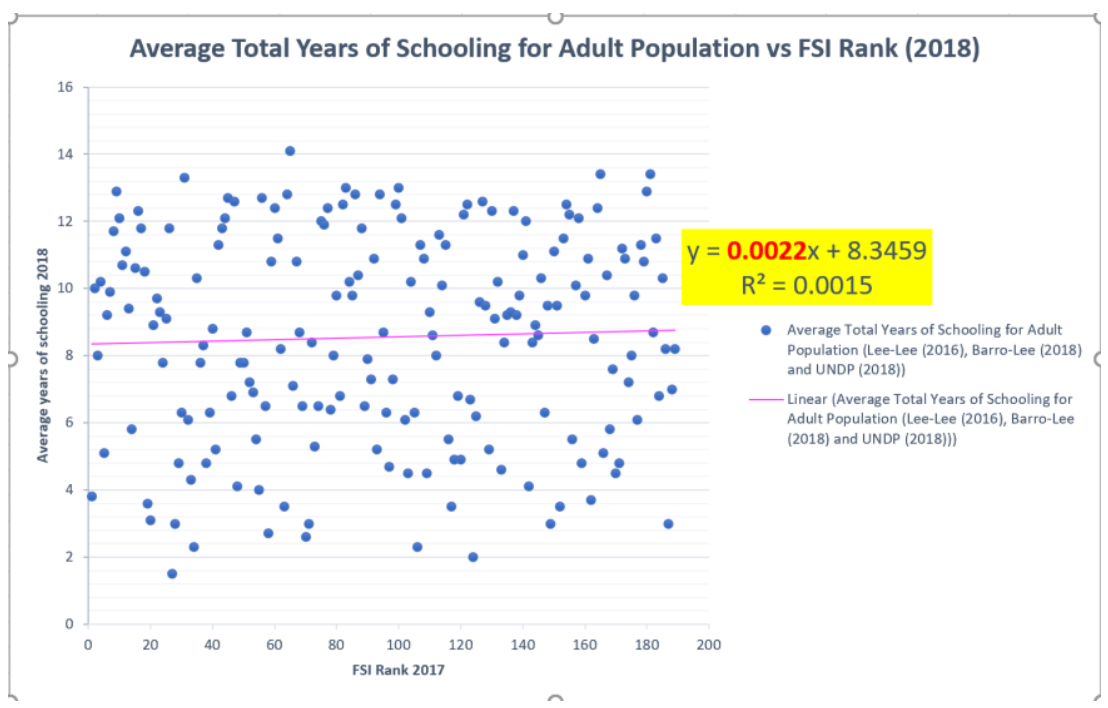

Figure 3 Average years of schooling \& FSI Rank 2018

In the third graph, a relatively weak relationship is showed between the years of schooling of citizens and states' stability. 190 states are counted here (Barro-Lee et al., 2018) while almost no evidence shows that the length of schooling helps to build stability. Possible reasons can be the quantity and quality of education [25], [28], [29], the unequal access to educational resources [30], [31]. As a result, though citizens in some countries have received relatively long years of education, the knowledge they learned may be helpless to national development.

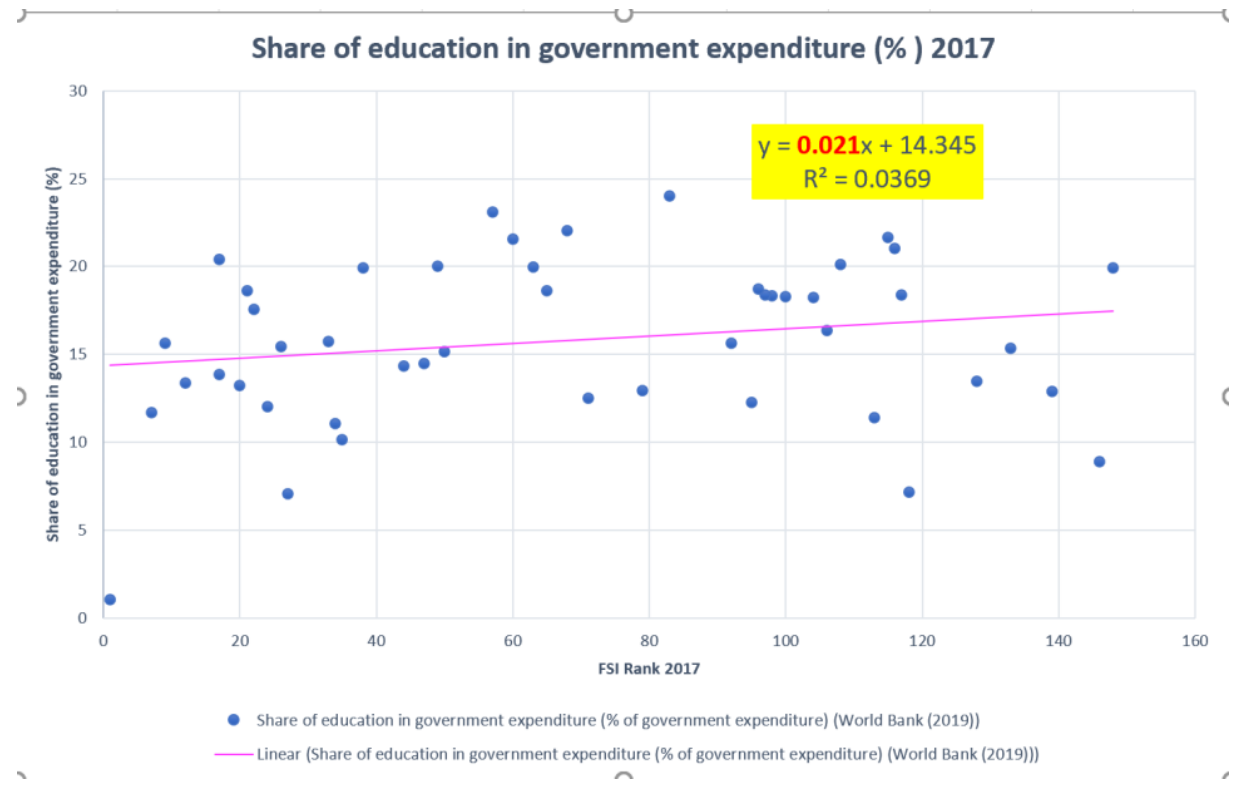

Figure 4 Share of government expenditure \& FSI Rank 2017

In the fourth graph, a clear and positive correlation can be seen between the share of government expenditure on education and its stability. 51 states are included and compared with each other[32]. High education spending does not have a decisive impact on national stability. There can be many complicated problems such as political corruption, the inefficient use of funds, and the quality of education. Also, if a country's government expenditure is so limited, even if education cost occupies a relatively large share, its utility is minimal compared with that of other high-welfare states.

\section{CONCLUSION}

The relationship between education and peacebuilding is a contested issue that has been discussing for many centuries. While some scholars believe that education can restrict human nature and civilized people, other scholars question the effectiveness of education. It is a complex problem that involves many interference factors such as the quantity, quality, culture, accessibility, and equality of education. The four correlation graphs above can only provide a brief relationship between some significant indicators in education and states' frangibility. In general, though, 
education has a positive impact on building peace, the impact of education on peace varies greatly from country to country and culture to culture.

\section{REFERENCES}

[1] N. P. Patil, "Role Of Education In Social Change," Int. Educ. E-Journal, vol. I, no. Ii, 2012.

[2] M. Taka, "The role of education in peacebuilding: learner narratives from Rwanda," J. Peace Educ., vol. 17, no. 1, 2020, doi: 10.1080/17400201.2019.1669146.

[3] E. W. Aslaksen, "The Role of Education," Lect. Notes Networks Syst., vol. 113, pp. 77-97, 2020, doi: 10.1007/978-3-030-40226-6_6.

[4] W. Pope, "Durkheim as a Functionalist," Sociol. Q., vol. 16, no. 3, 1975, doi: 10.1111/j.15338525.1975.tb00954.x.

[5] S. Rogosic, A. Maskalan, and A. Jurki, "What are the key roles of education?," Jahr, vol. 11, no. 22, 2020, doi: 10.21860/J.11.2.7.

[6] M. Ketola, International Foundation Programme Sociology FP006. London WC1B 5DN: University of London, 2019.

[7] A. F. Fagbamigbe, N. B. Kandala, and O. A. Uthman, "Decomposing the educational inequalities in the factors associated with severe acute malnutrition among under-five children in low- And middle-income countries," BMC Public Health, vol. 20, no. 1, 2020, doi: 10.1186/s12889-020-08635-3.

[8] Y. Teng, "Educational inequality and its determinants: Evidence for women in nine Latin American countries, 1950s-1990s," Revista de Historia Economica - Journal of Iberian and Latin American Economic History, vol. 37, no. 3. 2019, doi: 10.1017/S0212610919000107.

[9] J. A. Foley, D. Morris, P. Gounari, and F. Agostinone-Wilson, "Critical education, critical pedagogies, marxist education in the United States," J. Crit. Educ. Policy Stud., vol. 13, no. 3, 2015.

[10] C. Darwin, On the Origin of the Species. 1859.

[11] J. W. Meyer, "Institutional Theory and World Society," World Soc. Writings John W. Mayer, no. 2008, 2009.

[12] J. Donnelly, "The discourse of anarchy in IR," Int. Theory, vol. 7, no. 3, 2015, doi: $10.1017 / \mathrm{S} 1752971915000111$.

[13] J. M. Grieco, "Anarchy and the limits of cooperation: A realist critique of the newest liberal institutionalism," Int. Organ., vol. 42, no. 3, 1988, doi: 10.1017/S0020818300027715.

[14] R. Campanaro, International Relations. London, 2018.

[15] J. Kleidosty and I. Jackson, Leviathan. 2017.

[16] S. P. Rosen, War and human nature. Princeton University Press, 2009.

[17] S. P. Reyna, "Fry, Douglas P. (ed .): War, Peace, and Human Nature. The Convergence of Evolutionary and Cultural Views," Anthropos, vol. 109, no. 2, 2014, doi: 10.5771/0257-9774-2014-2-685.

[18] M. Verkuyten, “Assimilation ideology and outgroup attitudes among ethnic majority members," Gr. Process. Intergr. Relations, vol. 14, no. 6, 2011, doi: 10.1177/1368430211398506.

[19] J. S. Bunderson, "How work ideologies shape the psychological contracts of professional employees: Doctors' responses to perceived breach," J. Organ. Behav., vol. 22, no. 7, 2001, doi: 10.1002/job.112.

[20] L. M. Leslie, E. B. King, and J. A. Clair, "Work-life ideologies: The contextual basis and consequences of beliefs about work and life," Acad. Manag. Rev., vol. 44, no. 1, 2019, doi: 10.5465/amr.2016.0410.

[21] C. Li, U. Turmunkh, and P. P. Wakker, "Trust as a decision under ambiguity,” Exp. Econ., vol. 22, no. 1, 2019, doi: 10.1007/s10683-018-9582-3.

[22] A. E. Wendt, "Anarchy is what states make of it: The social construction of power politics," Uluslararasi Iliskiler, 2013.

[23] S. Aleksovski, O. Bakreski, and B. Avramovska, "Collective Security - The role of international organizations - Implications in international security order,” Mediterr. J. Soc. Sci., vol. 5, no. 27, 2014, doi: 10.5901/mjss.2014.v5n27p274.

[24] OECD, "Population with tertiary education (indicator)," 2021. https://data.oecd.org/eduatt/population-withtertiary-education.htm (accessed Jul. 31, 2021).

[25] M. Sas, K. Ponnet, G. Reniers, and W. Hardyns, "The role of education in the prevention of radicalization and violent extremism in developing countries," Sustain., vol. 12, no. 6, 2020, doi: 10.3390/su12062320.

[26] OECD, "Enrolment rate in early childhood education (indicator)," 2021. https://data.oecd.org/students/enrolment-rate-inearly-childhood-education.htm (accessed Jul. 31, 2021). 
[27] U. Lee-Lee , Barro-Lee, “Average total years of schooling for adults population," United Nations Development Programme, Human Development Report (2018 Statistical Update), 2018. https://ourworldindata.org/grapher/mean-years-ofschooling-1?tab=table (accessed Aug. 02, 2021).

[28] D. Filmer, H. Rogers, N. Angrist, and S. Sabarwal, "Learning-adjusted years of schooling (LAYS): Defining a new macro measure of education," Econ. Educ. Rev., vol. 77, 2020, doi: 10.1016/j.econedurev.2020.101971.

[29] L. Gabriel Ndijuye and P. Basil Tandika, "Towards Global Peace and Sustainability: Role of Education in Peace-Building in the Great Lakes Region of SubSaharan Africa," in Education, Human Rights and Peace in Sustainable Development, 2020.

[30] M. Ayub, "Poverty and Inequality," Glob. J. Emerg. Mark. Econ., vol. 5, no. 3, 2013, doi: 10.1177/0974910113505796.

[31] S. A. Asongu, S. Diop, and A. K. Addis, "Governance, Inequality and Inclusive Education in Sub-Saharan Africa," Forum Soc. Econ., 2020, doi: 10.1080/07360932.2020.1856166.

[32] UNESCO, "Share of education in government expenditure (\% of government expenditure) (World Bank (2019))," World Bank EdStats, 2019. https://ourworldindata.org/financing-education (accessed Aug. 02, 2021). 